PRZEGLĄD RUSYCYSTYCZNY 2020, nr 3(171)

(c) $\underset{\mathrm{BY}}{\mathrm{SA}} \mathrm{(i)}$
$\mathrm{DOI} 10.31261 / \mathrm{pr} .7894$

MATEUSZ JAWORSKI

UAM Poznań

(D ORCID: https://orcid.org/oooo-0oo2-4400-5546

\title{
О ХРУПКОСТИ ТРАДИЦИИ \\ И МОДЕЛИРОВАНИИ ПРОШЛОГО-БУДУЩЕГО В ПОЗДНЕМ ТВОРЧЕСТВЕ ВИКТОРА ПЕЛЕВИНА
}

\section{ON THE FRAGILITY OF TRADITION AND MODELING THE PAST-FUTURE IN THE LATE WORKS OF VICTOR PELEVIN}

The paper aims at interpreting two recent novels by Viktor Pelevin - Mafusail's Lamp and iPhuck 10 in the context of time-space, remembrance and oblivion. The analysis revealed the Russian writer's vast interest in the physical and philosophical theories related to the true nature of the Universe. Therefore, time and space are inextricably connected in the relevant novels as they form a whole network of parallel realities. Moreover, the realities do not function in the linear way, as human beings would like to perceive them. In Mafusail's Lamp time travel is possible, but the introduced modifications of the past make the future impossible (in fact, the amendment of the past leads to an utterly new time-space). On the other hand, time travel in iPhuck 10 takes an unorthodox form of world creation (in this case - a world struggling to revive traditional spiritual values), as remembrance in the novel calls for constructing a whole new world. Thus, time travel hardly makes any sense, as all possible worlds exist simultaneously.

Keywords: Pelevin, time-space, memory, time travel, tradition

Современное мировое искусство, в рамках которого литература не является исключением, наравне с сопровождающим ее дискурсом проявляет бо́льшую заинтересованность в онтологических вопросах, чем в типично гносеологическом напряжении между субъектом и объектом познания ${ }^{1}$. Эта тенденция наблю-

${ }^{1}$ Cm. B. McHale, Powieść postmodernistyczna, przeł. M. Płaza, Wydawnictwo Uniwersytetu Jagiellońskiego, Kraków 2012, s. 13. 
дается не только в контексте попытки уловить кажущуюся неуловимой текучесть действительности и ее типично пространственного (или - материалистического) понимания, но также в более сложном свете смутного пространства-времени. Данная категория оказывается как аналогом разработанного литературоведением и культуроведением хронотопа, понимаемого в духе Михаила Бахтина ${ }^{2}$, так и отражением значимости физических открытий, связанных с теорией относительности Альберта Эйнштейна и квантовой механикой Макса Планка (хотя стоит отметить, что термин хронотоп также взял свое начало в сфере естественных наук посредством Алексея Ухтомского ${ }^{3}$ ). Время, являвшееся до данного момента мировой истории не подвергающимся сомнениям линейным фактом, стало серой зоной многовекторности, исключающей причинно-следственный детерминизм4. Такая трактовка нелинейности человеческого восприятия бытия (и действительности) ведет к нескольким далеко не традиционным взглядам на настоящую природу реальности: 1) настоящее состояние Вселенной только минимально (или вообще не) чревато последствиями в виде ее будущего состояния; 2) воспринимаемая человеком Вселенная является лишь только одним из миров, раскладывающихся на Мультиверс параллельных (или потенциально пересекающихся) реальностей; 3) память о прошлом не должна ничем отличаться от памяти о будущем. С точки зрения интерпретатора новейшей русской литературы эти гипотезы, или точнее - мысленные эксперименты (ведь даже квантовая механика оперирует на уровне невероятно маленьких, микроскопических частиц, которые мы не сможем наблюдать даже при помощи мощнейших инструментов), несомненно, могут показаться особо любопытным контекстом прочтения литературного произведения.

2 См. например М. Бахтин, Собрание сочинений. Том 1. Философская эстетика 1920-x, Издательство Русские Словари, Языки славянской культуры, Москва 2003, c. 69-205.

3 Сам Бахтин признал влияние Ухтомского на свои размышления в тексте Формы времени и хронотопа в романе. См. М. Бахтин, Формы времени и хронотопа в романе. Очерки по исторической поэтике, [в:] Его же, Вопросы литературы и эстетики, Издательство Художественная литература, Москва 1975, с. 234-407.

4 См. например Ł. Lamża, O tym, co możliwe, konieczne i rzeczywiste, „Tygodnik Powszechny”, Wydanie specjalne: Wszystko co wiemy, 2018, № 1(6), c. 10-14. 
Вышеначерченная проблематика является идейным ядром и исходной точкой двух достаточно новых романов Виктора Пелевина - Лампы Мафусаила, или крайняя битва чекистов с масонами ${ }^{5}$ и $i$ Phuck $10^{6}$, опубликованных в 2016 и 2017 годах. Сомнения в достоверности человеческого восприятия времени, понимаемого как одностороннее протекание процессов от пункта А до пункта Б, заметны в творчестве русского прозаика с момента издания второй части его вампирического диптиха Бэтмана Аполло (2013). Однако в данном произведении играют они далеко не первостепенную роль, функционируя только в качестве орнамента, иронически комментирующего текущие события в России. Итак, протесты на Болотной площади 2012 года оказываются в Бэтмане Аполло лишь инструментом манипуляции спецслужб, которые по команде вампиров выполняют прошлое-будущее, записанное (хотя форма страдательного причастия прошедшего времени здесь не очень удачная; хотелось бы создать форму причастия будущего времени) в Ацтекском календаре.

В романе Лампа Мафусаила рассказывается история трех поколений семьи Можайских - Маркиана, Мафусаила и Крима, суть которой состоит не в довольно пошлом и грубоватом сюжете, а в необычной трактовке самой идеи памяти и идентичности. В начале текста Пелевина можем прочитать следующее: «Я вдруг понял, что вся моя память стала узорами света - и была уже не внутри меня, а вокруг. Собственно, все, что я видел, и было памятью» ${ }^{8}$. Под влиянием наркотических средств, примененных с целью покончить жизнь самоубийством, Крим - младший из рода - оказывается в состоянии эпифанического транса. Это состояние позволяет ему не только увидеть глубинную реальность, но прежде всего понять нелинейность и размытость пространства-времени, скрываемые от человеческого познания под покровом внушенной видимости. Для молодого брокера время и пространство сливаются, становясь смутной зоной неопреде-

5 В. Пелевин, Лампа Мафусаила, или крайняя битва чекистов с масонами, Издательство «Э», Москва 2016. В дальнейшем название сокращаем до: Лампа Мафусаила.

6 В. Пелевин, iPhuck 1o, Издательство «Э», Москва 2018.

7 В. Пелевин, Бэтман Аполло, Издательство «Эксмо», Москва 2013.

8 В. Пелевин, Лампа Мафусаила, или крайняя битва чекистов с масонами, Издательство «Э», Москва 2016, с. 31. 
ленности и неразличимости. К тому же переживаемые им события лишаются ощущения последовательности, а восприятие окружающего настоящего становится работой памяти - мифологический Абсолютный Ум (Всевидящий Глаз) лишь припоминает себе свою изначальную (бес)форму. Итак, восприятие оказывается лишь затруднительным процессом отождествления (слияния) внешней и умственной реальностей, причем умственный порядок доминирует благодаря своей априорности. В таком ракурсе познание сводится к воспроизведению мира из бездны Абсолютной Памяти, лишенной даже видимости движения (течения) и выполненной божественной, бесконечной инерцией.

Следует здесь отметить еще один важный момент - время в рамках сюжета романа неслучайно течет вопреки хронологии. В начале рассказа описывается судьба Крима, потом центральная для нашего анализа история его прадеда Маркиана, предшествующая масонской деятельности его деда Мафусаила. Весь сюжет объединяет персонаж агента спецслужб Капустина, совершающего путешествия по бескрайнему простору Мультиверса, т.е. передвигающегося из своего родного мира-времени в другие. В первой части романа рассказчик прямо ссылается на открытия естественных наук:

Дело тут не в суевериях, а в безжалостном научном знании. Если верить современным физикам, все вообразимые миры - если мы можем описать их словами - обязательно существуют где-то в мультиверсе хотя бы в виде симуляции. Отчего же, спрашивается, я не могу проснуться в одном из них? Именно в том, какой описываю?9.

Таким образом, будучи посланцем из еще-не-случившегося будущего, Капустин знакомится со всеми вышеперечисленными представителями семьи Можайских. Его задание заключается во введении незначительных изменений в прошлое. Оно непростое, так как слишком резкая модификация может привести к тотальной катастрофе, т.е. к полному исчезновению данной действительности. В тексте работа Капустина определяется следующим образом:

Видите ли, проходя через прошлое, мы в действительности ничего не меняем в том будущем, откуда прибыли. Мы просто начинаем путешество-

9 Там же, с. 63. 
вать по безмерности мультиверса. Если смотреть по уравнениям, вы не трансформируете свой прежний мир, а переходите в близкий к нему параллельный, уничтожая прошлый - но вам-то какая разница? В практически наблюдаемой реальности вы изменили мир, а Вселенная спружинила ${ }^{10}$.

Тема манипуляции прошлым занимает центральное место также в следующем (по хронологии - sic! - издания) романе Пелевина - iPhuck 10. В данном случае, однако, русский писатель изобретательно находит новую реконфигурацию ${ }^{11}$ для выражения нелинейности времени в виде виртуальной реальности, создаваемой при помощи сверхсовременных компьютерных технологий и смешанной с псевдоискусствоведческим дискурсом. Рассказ ведется то специальным алгоритмом (литературно-следственным роботом) Порфирием Петровичем, то талантливой и безжалостной программисткой-искусствоведом Марой, то очередным алгоритмом, что придает истории видимость достоверности из-за нескольких точек зрения. Сюжет романа опирается на нелегальную деятельность Мары, которая благодаря своим умениям и специальным знаниям в области программирования и нейронных сетей, в состоянии создавать полноценные артефакты в прошлом, или точнее генерировать-созидать прошлое с целью оставить в нем объекты искусства. Главный интерес Мары вызывает артистическое направление, приписываемое началу XXI века и определяемое с помощью слова «гипс» (или выражения «гипсовый век»). Сама героиня описывает его в разговоре с Порфирием следующим образом:

- А что такое «гипсовый век»? Какая-то периодизация?

- Скорее парадигма, связанная с историческим периодом. [...]

- [...] А почему такое название - «гипс»? [...]

- [...] У Делона Ведпровуа было эссе с названием «Гипсовая контрреформация». Оттуда это и пошло. Гипсовая контрреформация, по Ведровуа, была последней попыткой мировой реакции вдохнуть жизнь в старые формы и оживить их. Создать, как он пишет, франкенштейна из трупного материала культуры [...]. [...] Они [средний класс, интеллектуалы - М.Я.] лепят гипсовый саркофаг вокруг воображаемого трупа, выставляют вооруженную охрану и пытаются таким образом остановить

${ }^{10}$ Там же, с. 181.

11 Здесь имеем в виду ключевую с точки зрения поэтики текстов Пелевина категорию, разработанную нами в монографии M. Jaworski, Реконфигурация в романной поэтике Виктора Пелевина. Солипсизм - язык - история, Wydawnictwo Naukowe UAM, Poznań 2019. 


\section{О ХРУПКОСТИ ТРАДИЦИИ...}

время... Гипсовое искусство - это искусство, которое своим виртуальным молотом пытается разбить этот саркофаг. Или, наоборот, старается сделать его крепче ${ }^{12}$.

В таком ракурсе гипс оказывается символом памяти о культурном прошлом, последним проявлением тоски по духовной традиции. Однако стоит здесь подчеркнуть, что Пелевин считает эту ностальгию чем-то вроде работы горя - ведь традиционно понимая культура для героев романа несомненно мертва. Следовательно, гипс оказывается усилием мирового искусства приостановить процесс забвения своего собственного идейного и аксиологического ядра. Художественная деятельность напоминает здесь путешествие во времени, так как ее цель состоит не в моделировании будущего или настоящего, а в восстановлении прошлого, возвращении к нему. Живое искусство, словно констатирует Пелевин, мыслимо только в прошлом. Трагизм судеб Порфирия, Мары и Жанны состоит в том, что попытка «вспомнить-создать» прошлое оказывается ловушкой - мир искусства и духовных ценностей требует страдания и самопожертвования. Используя терминологию романа, можем подытожить, что саркофаг привлекателен только извне, так как всякое сознание (пусть даже искусственное как Жанна и Порфирий), находящееся внутри его, обречено на бесконечное горе.

События, описываемые в романе, происходят, однако, уже после этого времени - в эпоху единой, глобальной организации общественной и личной жизни людей. Хрупкость памяти о традиционных ценностях, метафорически выраженная с помощью образа забытого гипсового саркофага, привела человечество к точке полной неразличимости безграничной свободы и тотального рабства. В мире iPhuck 10 культура оказывается лишь только капиталовложением, искусство - рекламой, а бытие потреблением огромного количества продуктов и услуг. Счастье понимается лишь как отсутствие страдания. Мара - впечатляющий знаток истории искусства, чуткая любовница и тонкий программист - придумывает способ создавать (творческий процесс, видимо, нуждается в настоящей душевной боли, которая отсутствует в пространстве-времени Мары и Порфирия), что, однако, не означает «воссоздавать», настоящий гипс в прошлом. Именно поэтому с помощью доступного для нее оборудования она

${ }^{12}$ В. Пелевин, iPhuck 10, Издательство «Э», Москва 2018, с. 39-41. 
созидает (наподобие Бога-Демиурга) н о в ую в и р туа льн ню реальность прошлого - так называемый гипсовый кластер.

Следует отметить, что весь этот сюжет оказывается также ироническим метакомментарием русского писателя, так как Мара создает гипсовую реальность, переполненную печалью и страданием для корыстных, материалистических целей ${ }^{13}$. К тому же ради прибыли она готова не только отречься от так тонко интерпретируемых ею ценностей (или точнее - забыть их), но даже организовать убийство своих друзей и заставить единственное любимое ею существо постоянно страдать (ведь только в таких условиях создается гипсовое искусство). Мара, кажется, намекает Пелевин, - продукт с в о его времени. Именно поэтому ее финальное поражение в борьбе с Жанной (т.е. созданным ею искусственным интеллектом) и вечное отшельничество-творчество в гипсовом кластере наполняет ее бесконечным ужасом ${ }^{14}$. Мара успешно совершила путешествие во времени, но прошлое, в которое она отправилась не совпадает со знакомым ей случившимся миром, так как время-пространство оказывается запутанным множеством параллельных действительностей. В так понимаемом Мультиверсе, лишенном ограничений и точек опоры, почти невозможно отправиться в желаемую реальность.

Помимо очевидных сходств, несомненно, стоит здесь отметить интересную тонкость, отличающую подход к проблеме памяти в анализируемых нами романах. Герои в $i P h u c k 10$ в сущности л иш ены прошл ого. Процесс вспоминания здесь буквально означает создание (материального) мира. Однако интересно, что создание гипсового кластера, переполненного страданием его единственного жителя, в отличие от путешествий Капустина, не связано с модификацией прошлого или будущего-настоящего, а больше напоминает ностальгию или вышеупомянутую работу горя.

13 Здесь стоит припомнить, что многие критики упрекают самого Пелевина в коммерческом подходе к литературе. Писатель словно ведет с ними ироническую игру в рамках своих текстов, начиная с $T$. Поведение и мотивировку Мары несомненно можем интерпретировать также в данном ракурсе. См. А. Немзер, Как я упустил карьеру, http://pelevin.nov.ru/stati/o-nemz/1.html, (доступ: 30.08.2019); Д. Быков, П. Басинский, Два мнения о романе Виктора Пелевина «Чапаев и Пустота», http://pelevin.nov.ru/stati/o-dva/1.html (10.10.2016).

${ }^{14}$ См. В. Пелевин, iPhuck 10, Издательство «Э», Москва 2018, с. 396-397. 


\section{О ХРУПКОСТИ ТРАДИЦИИ...}

Настоящие вступительные размышления на тему трактовки пространства-времени (хронотопа) и памяти/забвения в выбранных произведениях Виктора Пелевина, несомненно, являются любопытным интерпретационным контекстом. Стоит подчеркнуть заинтересованность автора Чапаева и Пустоты в проблеме восприятия действительности и нелинейности времени. Следует здесь заметить стыковой характер анализируемых текстов - их прочтение значительно обогащается философским и физическим аспектами. Любопытным примером реконфигурационных реализаций идеи манипуляции прошлым оказалось представление идеи памяти как носителя культурных ценностей в iPhuck 10. Данный контекст безусловно заслуживает исследовательского внимания и нуждается в дальнейшей, более подробной разработке и интерпретационном усилии.

\section{REFERENCES}

Bakhtin, Mikhail. Sobraniye sochineniy. Tom 1. Filosofskaya estetika 1920-kh. Moskva: Izdatel'stvo Russkiye Slovari. Yazyki slavyanskoy kul'tury. 2003 [Бахтин, Михаил. Собрание сочинений. Том 1. Философская эстетика 1920-х. Москва: Издательство Русские Словари. Языки славянской литературы. 2003].

Bakhtin, Mikhail. Voprosy literatury i estetiki. Moskva: Izdatel'stvo Khudozhestvennaya literatura. 1975 [Бахтин, Михаил. Вопросы литературы и эстетики. Москва: Издательство Художественная литература, 1975].

Bykov, Dmitriy. Basinskiy, Pavel. Dva mneniya o romane Viktora Pelevina "Chapayev i Pustota." 10 November 2019 <http://pelevin.nov.ru/stati/o-dva/1. html>. [Быков, Дмитрий. Басинский, Павел. Два мнения о романе Виктора Пелевина "Чапаев и Пустота." 10.11.2019 <http://pelevin.nov.ru/stati/odva/1.html $>$.

Jaworski, Mateusz. Rekonfigutratsiya $v$ romannoy poetike Viktora Pelevina. Solipsizm - yazyk - istoria. Poznań: Wydawnictwo Naukowe UAM, 2019 [M. Jaworski, Реконфигурация в романной поэтике Виктора Пелевина. Солипсизм - язык - история, Poznań: Wydawnictwo Naukowe UAM, 2019].

Lamża, Łukasz. "O tym, co możliwe, konieczne i rzeczywiste.” Tygodnik Powszechny 2018, no. 1(6). 10-14.

McHale, Brian. Powieść postmodernistyczna. Transl. Płaza, Maciej. Kraków: Wydawnictwo Uniwersytetu Jagiellońskiego. 2012.

Nemzer, Andrey. Kak ya upustil kar'yeru. 10 November $2019<$ http://pelevin. nov.ru/stati/o-nemz/1.html> [Немзер. Андрей. Как я упустил карьеру. 10.11.2019<http://pelevin.nov.ru/stati/o-nemz/1.html>].

Pelevin, Viktor. B·etman Apollo. Moskva: Izdatel'stvo "Eksmo." 2013 [Пелевин Виктор. Бэтман Аполло. Москва: Издательство “Эксмо.” 2013]. 


\section{MATEUSZ JAWORSKI}

Pelevin, Viktor. iPhuck 1o, Moskva: Izdatel'stvo “Ėksmo.” 2018 [Пелевин, Виктор. iPhuck 10. Москва: Издательство “Эксмо.” 2018].

Pelevin, Viktor. Lampa Mafusaila, ili kraynyaya bitva chekistov s masonami. Moskva: Izdatel'stvo "E”. 2016 [Пелевин, Виктор. Лампа Мафусаила, или крайняя битва чекистов с масонами. Москва: “Э.” 2016]. 